\title{
Meta-analysis of the relationship between depression and diabetic retinopathy.
}

\author{
Chao Wu, Zhipeng You*
}

Department of Ophthalmology, the Second Affiliated Hospital of Nanchang University, Jiangxi Province, PR China

\begin{abstract}
Objective: To study the correlation between depression and the risk of Diabetic Retinopathy (DR).

Methods: A total of 268 articles were obtained from PubMed, Web of Science, Science Direct and Ovid between January 2000 and September 2017, combined with retrospective retrieval of literature. Stata12.0 was utilized for statistical data and the OR $(95 \%$ CI $)$ values were obtained by means of metaanalysis.

Results: A total of 4912 cases and 11641 controls were incorporated in the study from 19 literatures. The results of the meta-analysis demonstrated that the combined OR $(95 \% \mathrm{CI})$ value was 1.43 (1.21-1.69), while the risk of DR in patients with diabetes mellitus was augmented by 0.43 times than that in the normal diabetic patients. After grouping of diabetic patients, the combined OR (95\% CI) value was 2.18 (0.91-5.24), $1.5(1.18-1.92)$ and $1.15(0.87-1.52)$, respectively. On the other hand, after grouping of different subjects, the OR $(95 \% \mathrm{CI})$ value was $1.28(1.03-1.59)$ and $1.62(1.28-2.06)$, respectively.

Conclusion: Depression is among the substantial risk factors for the pathogenesis of DR. The targeted intervention will help in reducing the risk of DR.
\end{abstract}

Keywords: Depression, Diabetic retinopathy, Meta-analysis.

Accepted on November 8, 2017

\section{Introduction}

Diabetic Retinopathy (DR) is the most common chronic complication of diabetes mellitus and the first blinding disease in working-age population [1]. With the precipitous growth of the national economy as well as changes in people's lifestyles, the number of patients with diabetes mellitus has also been increased. According to the data published by WHO in 2014, the number of global diabetes patients has escalated to 422 million. Moreover, its prevalence rate in people aged above 18 years has also been reported to be at $8.5 \%$ [2]. With the prolongation of the course of diabetes mellitus, the prevalence of DR has also continually increased year by year. The data exhibit that the prevalence of DR is $34.6 \%$ [3]. Depression is a common chronic disease in the population, commonly occurring with diabetes mellitus. Studies have confirmed that the prevalence of depression in the diabetic population is twice that of the general population [4]. Diabetes mellitus with depression usually increases the burden of disease, while reducing treatment compliance and leading to a decline in life quality as well as an increase in mortality [5-9]. Other studies have expressed that depression has substantial correlations with complications of diabetes mellitus [10]. However, there is less research on the impact of depression on incidences of DR. In this way, meta-analysis was carried out for the relationship between depression and DR to further explicate the impact of depression on the incidence of DR.

\section{Materials and Methods}

Information: With "depression" or "depressive disorder", "diabetic retinopathy" and "diabetes complications" as the keywords, and English as the literature language, PubMed, Web of Science, Science Direct, Ovid as well as other English databases were retrieved, together with literatures retrospect. Furthermore, literatures regarding the risk of depression along with DR published both at home and oversees were collected. The time range was from September 2000 to 2017. In the end, a total of 268 articles were retrieved.

\section{Inclusion and exclusion criteria}

(1) Inclusion criteria of literatures: 1) case-control studies or cohort studies on the risk of depression and DR; 2) adult subjects with types I and II diabetes mellitus (ranging from 18 y), along with the sample size $\geq 25$; (2) Exclusion criteria: In accordance with the literature quality evaluation scale (NOS) prepared by Wells et al. [11] and the self-defined standard, the quality of literature had been estimated. Additionally, the literatures with poor quality, repetition, and unknown data description as well as those with too little report were eliminated. The blind method was utilized in literature excerpts to reduce bias. 


\section{Statistical analysis}

The collected data were analysed by means of the Stata12.0 software. As well, the heterogeneity test was carried out through the $\mathrm{Q}$ test. $\mathrm{P}<0.1$ and $\mathrm{I}^{2} \geq 50 \%$ presented that the heterogeneity existed [12]. The OR $(95 \% \mathrm{CI})$ value was estimated after selecting the fixed effect model or the random effect model on the basis of the results of heterogeneity test. Meta-regression analysis [13] was the undertaken for analyzing the source of heterogeneity $(\mathrm{P}<0.1$ suggested the heterogeneity), while the possible heterogeneity factors had been analysed in sub-group; to monitor the stability degree of combined effect in this study. The literatures with large sample size as well as those with large differences were, however, eliminated one by one and the sensitivity analysis performed thereafter. If there was no change in inferences in the sensitivity analysis, the stability of literature included was good; otherwise, the reasons for various deductions were analysed. The publication bias of this study was then tested through the Begg rank correlation method together with the Egger regression method [14]. $\mathrm{P}<0.10$ suggested that there was publication bias, and the corresponding funnel map was drawn.

\section{Results}

\section{Characteristics of literatures included}

Among the 268 literatures retrieved, a total of 20 independent studies as well as a total of 19 had been incorporated in line with the inclusion and exclusion criteria of literature by use of the blind method [15-33]. These included 3 articles about type I diabetes, 12 about type II diabetes, 5 about types I and II; and 1 article studied the types I and II diabetes independently (Figure 1). A total of 4912 cases of DR cases along with 11641 controls were registered, as shown in Table 1.

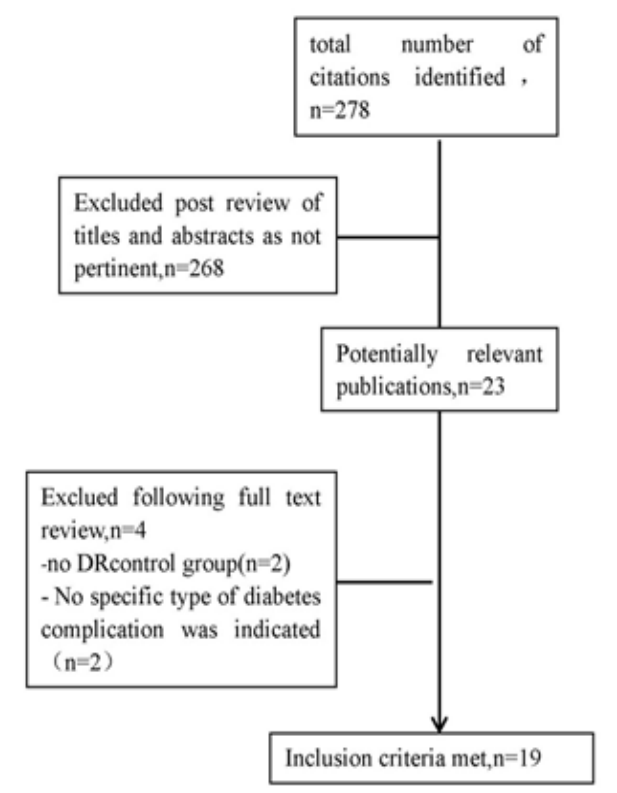

Figure 1. Flow diagram of the selection process.

\section{Relationship between depression and DR}

The results of meta-analysis showed that the combined $\mathrm{OR}=1.43,95 \% \mathrm{CI}=1.21-1.69$, suggesting that the risk of $\mathrm{DR}$ in patients with diabetic depression was increased by 0.43 times (Figure 2).

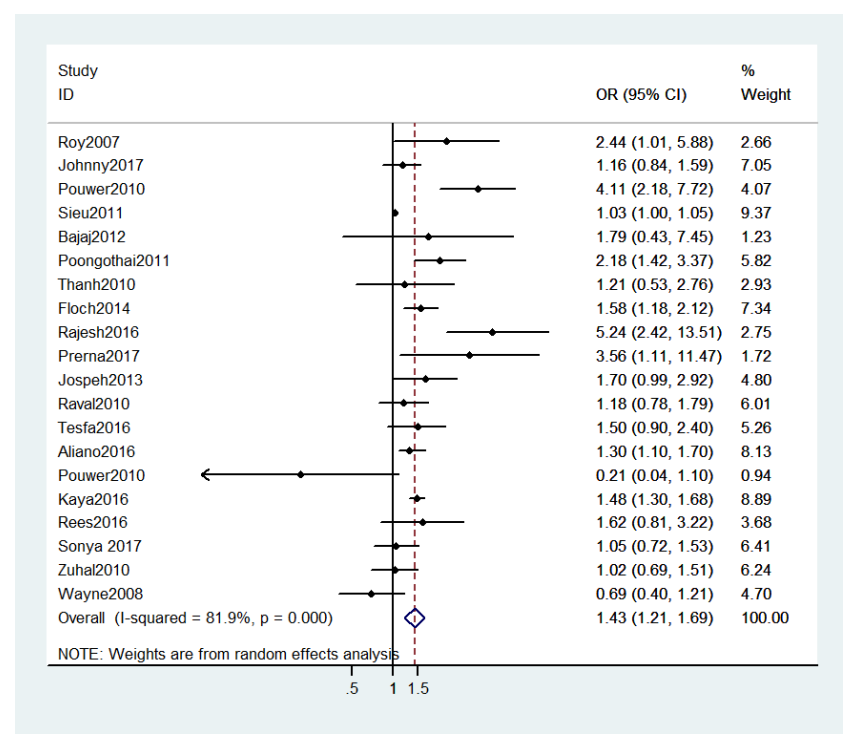

Figure 2. Forest map of the relationship between depression and $D R$.

\section{Heterogeneity test results}

Through heterogeneity test, we found out that the results were statistically significant $\left(\chi^{2}=104.96, \quad \mathrm{P}<0.01, \quad \mathrm{I}^{2}=81.9 \%\right)$, showing that this study was heterogeneous. As per the heterogeneity test results, the random effect model ought to be selected.

\section{Meta regression analysis}

Diabetes type $(\mathrm{P}=0.091, \mathrm{M} 1)$ and subjects $(\mathrm{P}=0.044, \mathrm{M} 1)$ had been screened as the probable heterogeneity factors from factors that may influence the heterogeneity (type of diabetes, study subjects, sample size, HbA1C level, and duration of illness) through determining three models (M1-M3). Meta regression results are illustrated in Table 2.

\section{Sub-group analysis}

As per the heterogeneity impacting factors screened through meta regression, cases were separated into three sub-groups (Types 1, 2 and mixed types 1 and 2) in 20 studies in accordance with the type of diabetes; and two subgroups were divided as developed and low- and middle-income countries. The Q, P, $\mathrm{I}^{2}$, OR and $95 \% \mathrm{CI}$ in each sub-group analysis are indicated in Table 3.

\section{Sensitivity analysis results and publication bias}

The literatures with large differences or large sample size (greater than the median sample size) were exempted and the meta-analysis was performed successively, and the results did not change substantially, illustrating that the results of this 
Meta-analysis of the relationship between depression and diabetic retinopathy

study were stable, reliable and credible (Table 4). The funnel map was not symmetrical, which suggests that there may be publication bias. However, the results of Begg rank correlation method indicated no publication bias $(\mathrm{Z}=0.10, \mathrm{P}=0.992)$, even though Egger regression test results exhibited that there might have been publication bias ( $\mathrm{t}=0.10, \mathrm{P}=0.992)$ (Figure 3 ).

Table 1. Literatures included into the meta-analysis.

\begin{tabular}{|c|c|c|c|c|c|c|}
\hline Literature no. & Author & Year & Diabetes type & Case group (n) & Control group (n) & OR (95\% Cl) \\
\hline [9] & Roy & 2007 & Type I & 211 & 104 & $2.44(1.01-5.88)$ \\
\hline [19] & Johnny & 2017 & Type I & 207 & 115 & $1.16(0.84-1.59)$ \\
\hline [26] & Pouwer & 2010 & Type I & 17 & 317 & $4.11(2.18-7.72)$ \\
\hline [6] & Sieu & 2011 & Type II & 480 & 1875 & $1.026(1.002-1.051)$ \\
\hline [7] & Bajaj & 2012 & Type II & 9 & 51 & $1.786(0.428-7.448)$ \\
\hline [8] & Poongothai & 2011 & Type II & 139 & 708 & $2.185(1.417-3.371)$ \\
\hline [15] & Thanh & 2010 & Type II & 49 & 43 & $1.213(0.533-2.759)$ \\
\hline [16] & Floch & 2014 & Type II & 256 & 730 & $1.582(1.18-2.119)$ \\
\hline [17] & Rajesh & 2016 & Type II & 45 & 365 & $5.241(2.421-13.509)$ \\
\hline [20] & Prerna & 2017 & Type II & 23 & 77 & $3.5625(1.1069-11.4656)$ \\
\hline [22] & Jospeh & 2013 & Type II & 84 & 146 & $1.7(0.99-2.92)$ \\
\hline [23] & Raval & 2010 & Type II & 116 & 184 & $1.18(0.78-1.79)$ \\
\hline [24] & Tesfa & 2016 & Type II & 140 & 140 & $1.5(0.9-2.4)$ \\
\hline [25] & Aliano & 2016 & Type II & 29 & 79 & $1.3(1.1-1.7)$ \\
\hline [27] & Pouwer & 2010 & Type II & 22 & 439 & $0.21(0.04-1.1)$ \\
\hline [3] & Kaya & 2016 & Types I and II & 1922 & 2361 & $1.478(1.297-1.684)$ \\
\hline [5] & Rees & 2016 & Types I and II & 305 & 192 & $1.62(0.81-3.22)$ \\
\hline [13] & Sonya & 2017 & Types I and II & 260 & 1054 & $1.05(0.72-1.53)$ \\
\hline [14] & Zuhal & 2010 & Types I and II & 205 & 295 & $1.02(0.689-1.512)$ \\
\hline [21] & Wayne & 2008 & Types I and II & 393 & 2366 & $0.69(0.4-1.21)$ \\
\hline
\end{tabular}

Table 2. Meta regression results in 20 studies.

\begin{tabular}{|c|c|c|c|c|c|c|c|c|c|c|c|c|}
\hline & \multicolumn{3}{|l|}{ Coefficient } & \multicolumn{3}{|l|}{$S_{x}$} & \multicolumn{3}{|l|}{$\mathbf{t}$} & \multicolumn{3}{|l|}{$\mathbf{P}$} \\
\hline & M1 & M2 & M3 & M1 & M2 & M3 & M1 & M2 & M3 & M1 & M2 & M3 \\
\hline $\begin{array}{l}\text { Diabetes } \\
\text { type }\end{array}$ & -0.3392934 & -0.3350529 & -0.3156062 & 0.1558374 & 0.1922548 & 0.2287884 & -2.18 & -1.74 & -1.38 & 0.044 & 0.101 & 0.189 \\
\hline Area & 0.3616181 & 0.3640878 & 0.3651689 & 0.201931 & 0.2132545 & 0.2461649 & 1.79 & 1.71 & 1.48 & 0.091 & 0.107 & 0.16 \\
\hline Sample size & - & -0.0000128 & -0.0000382 & - & 0.0000971 & 0.0001331 & - & -0.13 & -0.29 & - & 0.896 & 0.778 \\
\hline $\mathrm{HbA} 1 \mathrm{C}$ & - & - & -0.100507 & - & & 0.2928282 & - & & -0.31 & - & & 0.762 \\
\hline $\begin{array}{l}\text { Disease } \\
\text { year }\end{array}$ & - & - & 0.6989897 & - & & 0.6104457 & - & & 0.07 & - & & 0.946 \\
\hline
\end{tabular}

Table 3. Analysis results of different sub-groups.

\begin{tabular}{|c|c|c|c|c|c|c|}
\hline Subgroup factor & Grouping criteria & Number of documents & $\mathbf{Q}$ & $\mathbf{P}$ & $\mathrm{I}^{2}(\%)$ & $\begin{array}{l}\text { OR }(95 \% \mathrm{Cl}) \text { of combined } \\
\text { effect }\end{array}$ \\
\hline Diabetes type & Type I & 3 & 13.32 & 0.001 & 85 & $2.18(0.91-5.24)$ \\
\hline
\end{tabular}




\begin{tabular}{lllllll}
\hline & Type II & 12 & 52.21 & 0 & 78.9 & $1.5(1.18-1.92)$ \\
\cline { 2 - 7 } & Types I and II & 5 & 11.43 & 0.022 & 65 & $1.15(0.87-1.52)$ \\
\hline Subject & $\begin{array}{l}\text { Europe and the United } \\
\text { States }\end{array}$ & 11 & 42.6 & 0 & 76.5 & $1.28(1.03-1.59)$ \\
\cline { 2 - 7 } & Asia and Africa & 9 & 18.43 & 0.018 & 56.6 & $1.62(1.28-2.06)$ \\
\hline
\end{tabular}

Note: assignment of subjects in Meta regression: 1: United States+Canada+Netherlands+Australia+France+Spain; 2: India+Ethiopia+Turkey+Japan.

Table 4. Sensitivity analysis of meta-analysis results.

\begin{tabular}{|c|c|c|c|}
\hline $\begin{array}{l}\text { Operation } \\
\text { no }\end{array}$ & $\begin{array}{l}\text { Research literature } \\
\text { excluded }\end{array}$ & $\begin{array}{l}\text { OR }(95 \% \quad \mathrm{Cl}) \\
\text { after exclusion }\end{array}$ & $\begin{array}{l}\text { Whether the } \\
\text { results change }\end{array}$ \\
\hline 1 & 3 & $1.43(1.19-1.72)$ & No \\
\hline 2 & 17 & $1.37(1.16-1.62)$ & No \\
\hline 3 & 6 & $1.47(1.24-1.74)$ & No \\
\hline 4 & 8 & $1.39(1.17-1.64)$ & No \\
\hline 5 & 16 & $1.42(1.19-1.69)$ & No \\
\hline 6 & 27 & $1.45(1.3-1.72)$ & No \\
\hline 7 & 5 & $1.42(1.20-1.69)$ & No \\
\hline 8 & 13 & $1.46(1.22-1.75)$ & No \\
\hline 9 & 14 & $1.46(1.22-1.75)$ & No \\
\hline 10 & 21 & $1.48(1.24-1.76)$ & No \\
\hline
\end{tabular}

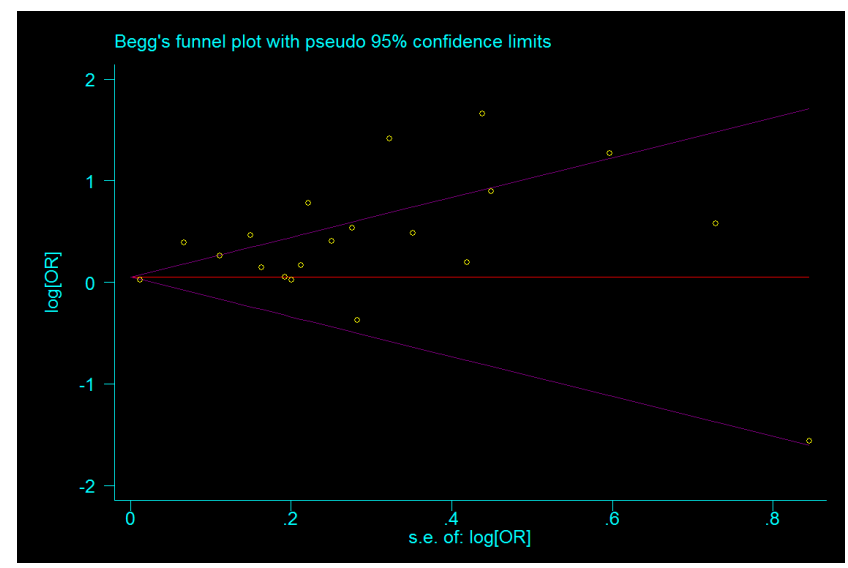

Figure 3. Funnel map of publication bias of literatures selected.

\section{Discussion}

The results of the meta-analysis illustrated that the OR $(95 \%$ CI) value of DR in patients with diabetes mellitus was 1.43 (1.21-1.69), showing that the depression is a risk factor for DR. On the other hand, the type of diabetes mellitus and the demographic characteristics of the study population are also considered to have significant impacts on the risk of DR. The results of this investigation were realized to be consistent with the previous studies on the relationship between depression and DR. Mary [10] studied and demonstrated that depression has a significant correlation with DR. Chen [34] also investigated and argued that DR in patients with depression is not uncommon, and that depression worsens the condition of retinopathy. In the study on type I diabetes mellitus $(\mathrm{OR}=2.18$, (95\% CI: 0.91-5.24)) and the mixed study on type I and type 2 diabetes mellitus $(\mathrm{OR}=1.15$, (95\% CI: 0.87-1.52), depression is not found to be correlated with the incidence of DR. This may be due to the fact that types I and II diabetes mellitus are caused by different factors. Due to the different onset age, duration and treatment, further studies are needed in this direction.

In this study, meta-analysis was realized to have certain limitations. First, the number of literatures included in the study was limited. Most particularly, in the subgroup analysis, the number of articles that could be studied in every subgroup was relatively small, which led to unstable heterogeneity analysis results. Second, due to the various definitions and diagnostic criteria of depression and DR, together with the different races and sample size, there was a potential selective bias caused. Additionally, only 3 out of 19 literatures were found to be prospective cohort studies for the study. The remaining 16 were cross-sectional studies. Therefore, we cannot establish the causal relationship between depression and DR. As such, more prospective cohort studies are needed for analyzing the causal relationship between depression and DR. Last, we cannot ignore the possibility that diabetes causes both depression and also DR. If this is the case, then the diabetes would be the mystifying factor in our meta-analysis.

Meta regression can be applied in identifying and screening the main factors for heterogeneity, and in analyzing the heterogeneous sources, which has a guiding significance in further data collection in the future. At the same time, it offers sub-group basis for the succeeding sub-group analysis. In the meta regression model for this study, the reasons for heterogeneity were screened. To avoid missing crucial factors, the test level $\alpha$ was expanded to 0.1 , and each influencing factor in regression model had been provided for every research; if it only existed in some original literatures, Meta regression was not appropriate [13]. In this present study, the type of diabetes mellitus as well as the study population was provided by the original literature.

Sensitivity analysis results indicated that the results of this examination were better and reliable. In general, 11 out of 20 literatures included in the study were found to be negative whereas only 9 were positive. The number of positive results was the same as that of negative results. In addition, the Begg rank correlation results exhibited no publication bias, either. 
From our research, it is obvious that the importance of prevent and treat depression in diabetes patients, which is usually ignored by Chinese doctors.

\section{References}

1. Klein BEK. Overview of epidemiologic studies of diabetic retinopathy. Ophthal Epidemiol 2007; 179-183.

2. World Health Organization. Global Report on Diabetes 2016.

3. Yau JWY, Rogers SL, Kawasaki R. Global prevalence and major risk factors of diabetic retinopathy. Diab Care 2012; 35: 556-564.

4. Anderson RJ, Freedland KE, Clouse RE. The prevalence of comorbid depression in adults with diabetes: a metaanalysis. Diab Care 2001; 24: 1069.

5. Ludman EJ, Katon W, Russo J. Depression and diabetes symptom burden. Gene Hosp Psych 2004; 26: 430-436.

6. Egede LE, Ellis C. Diabetes and depression: global perspectives. Diab Res Clinic Pract 2010; 87: 302-312.

7. Lin EHB, Katon W, Korff MV. Relationship of depression and diabetes self-care, medication adherence, and preventive care. Diab Care 2004; 27: 2154.

8. Brown GC, Brown MM, Sharma S. Quality of life associated with diabetes mellitus in an adult population. $\mathrm{J}$ Diab Compl 2000; 14: 18-24.

9. Rustad JK, Musselman DL, Nemeroff CB. The relationship of depression and diabetes: pathophysiological and treatment implications. Psychoneuroendocrinol 2011; 36: 1276-1286.

10. De GM, Anderson R, Freedland KE. Association of depression and diabetes complications: a meta-analysis. Psychosomat Med 2001; 63: 619.

11. Wells G, Shea B, OConnell D. The Newcastle-Ottawa Scale (NOS) for assessing the quality of nonrandomised studies in meta-analyses. Ottawa Hosp 2012; 7.

12. Higgins J, Thompson S. Quantifying heterogeneity in a meta-analysis. Stat Med 2002; 21: 1539-1558.

13. Shi XQ, Wang ZZ. Application of meta regression and subgroup analysis in heterogeneous treatment. Chinese J Epidemiol 2008; 29: 497-501.

14. Egger M, Smith G, Schneider M. Bias in meta-analysis detected by a simple, graphical test. Br Med J 1997; 7109: 629-634.

15. Ishizawa $\mathrm{K}$, Babazono $\mathrm{T}$, Horiba $\mathrm{Y}$. The relationship between depressive symptoms and diabetic complications in elderly patients with diabetes: analysis using the Diabetes Study from the Center of Tokyo Womens Medical University (DIACET). J Diab Compl 2016; 30: 597-602.

16. Rees G, Xie J, Fenwick EK. Association between diabetesrelated eye complications and symptoms of anxiety and depression. JAMA Ophthalmol 2016; 134.

17. Sieu N, Katon W, Lin EHB. Depression and incident diabetic retinopathy: a prospective cohort study. Gene Hosp Psych 2011; 33: 429-435.
18. Bajaj S, Agarwal SK, Varma A. Association of depression and its relation with complications in newly diagnosed type 2 diabetes. Ind J Endocrinol Metabol 2012; 16: 759-763.

19. Poongothai S, Anjana RM, Pradeepa R. Association of depression with complications of type 2 diabetes-the Chennai Urban Rural Epidemiology Study (CURES- 102). J Assoc Physicians India 2011; 59: 644-648.

20. Roy MS, Roy A, Affouf M. Depression is a risk factor for poor glycemic control and retinopathy in AfricanAmericans with type 1 diabetes. Psychosom Med 2007; 69: 537-542.

21. Deschênes SS, Burns RJ, Pouwer F. Diabetes complications and depressive symptoms: prospective results from the Montreal diabetes health and well-being study. Psychosom Med 2017; 1.

22. Saglam AZS. The frequency of depression in Turkish patients with diabetes and diabetic complications. Endocrinologist 2010; 20: 19-22.

23. Nguyen TT, Wong TY, Islam FM. Evidence of early retinal microvascular changes in patients with type 2 diabetes and depression. Psychosom Med 2010; 72: 535.

24. Le FJ, Doucet J, Bauduceau B. Retinopathy, nephropathy, peripheral neuropathy and geriatric scale scores in elderly people with type 2 diabetes. Diab Med J Br Diab Assoc 2014; $31: 107$.

25. Rajput R, Gehlawat P, Gehlan D. Prevalence and predictors of depression and anxiety in patients of diabetes mellitus in a tertiary care center. Ind J Endocrinol Metabol 2016; 20: 746-751.

26. Bai JW, Lovblom LE, Cardinez M. Neuropathy and presence of emotional distress and depression in longstanding diabetes: Results from the Canadian study of longevity in type 1 diabetes. J Diab Compl 2017.

27. Bahety P, Agarwal G, Khandelwal D. Occurrence and predictors of depression and poor quality of life among patients with type-2 diabetes: a Northern India perspective. Ind J Endocrinol Metabol 2017; 21: 564-569.

28. Katon W, Russo J, Lin EH. Depression and diabetes: factors associated with major depression at five-year follow-up. Psychosom 2009; 50: 570-579.

29. Joseph N, Unnikrishnan B, Raghavendra BYP. Proportion of depression and its determinants among type 2 diabetes mellitus patients in various tertiary care hospitals in Mangalore city of South India. Ind J Endocrinol Metabol 2013; 17: 681-688.

30. Raval A, Dhanaraj E, Bhansali A. Prevalence and determinants of depression in type 2 diabetes patients in a tertiary care centre. Ind J Med Res 2010; 132: 195-200.

31. Habtewold TD, Alemu SM, Haile YG. Sociodemographic, clinical, and psychosocial factors associated with depression among type 2 diabetic outpatients in Black Lion General Specialized Hospital, Addis Ababa, Ethiopia: a cross-sectional study. BMC Psychiatry 2016; 16: 103.

32. Urrutiaaliano D, Segura ER. Depressive symptoms and type 2 diabetes mellitus in outpatients of an Armed Forces 
hospital in Lima, Peru, 2012: a cross-sectional study. Medwave 2016; 16: 6435.

33. Pouwer F, Geelhoedduijvestijn PH, Tack CJ. Prevalence of comorbid depression is high in out-patients with Type 1 or Type 2 diabetes mellitus. Results from three out-patient clinics in the Netherlands. J Br Diab Assoc 2010; 27: 217-224.

34. Chen X, Lu L. Depression in diabetic retinopathy: a review and recommendation for psychiatric management. Psychosomatics 2016; 57: 465-471.

\section{*Correspondence to}

Zhipeng You

Department of Ophthalmology

The Second Affiliated Hospital of Nanchang University

PR China 